\title{
A comparison of melatonin and $\alpha$-lipoic acid in the induction of antioxidant defences in L6 rat skeletal muscle cells
}

\author{
Gaia Favero • Luigi Fabrizio Rodella • Lorenzo Nardo • Lorena Giugno • \\ Marco Angelo Cocchi • Elisa Borsani • Russel J. Reiter • Rita Rezzani
}

Received: 15 June 2015 / Accepted: 28 July 2015 / Published online: 7 August 2015

(C) The Author(s) 2015. This article is published with open access at Springerlink.com

\begin{abstract}
Aging is characterized by a progressive deterioration in physiological functions and metabolic processes. The loss of cells during aging in vital tissues and organs is related to several factors including oxidative stress and inflammation. Skeletal muscle degeneration is common in elderly people; in fact, this tissue is particularly vulnerable to oxidative stress since it requires large amounts of oxygen, and thus, oxidative damage is abundant and accumulates with increasing age. Melatonin ( $N$-acetyl-5-methoxytryptamine) is a highly efficient scavenger of reactive oxygen species and it also exhibits beneficial anti-inflammatory and anti-aging effects. This study investigated the susceptibility of rat L6 skeletal muscle cells to an induced oxidative stress following their exposure to hydrogen peroxide $(50 \mu \mathrm{M})$ and evaluating the potential
\end{abstract}

G. Favero • L. F. Rodella • L. Giugno • M. A. Cocchi •

E. Borsani $\cdot$ R. Rezzani $(\bowtie)$

Division of Anatomy and Physiopathology, Department of Clinical and Experimental Sciences, University of Brescia, Viale Europa 11, 25123 Brescia, Italy

e-mail: rita.rezzani@unibs.it

L. F. Rodella $\cdot$ E. Borsani $\cdot$ R. Rezzani

University of Brescia, Brescia, Italy

L. Nardo

Department of Radiology and Biomedical Imaging, University of California San Francisco, 185 Berry Street, Suite 350, San

Francisco, CA 94107, USA

\section{R. J. Reiter}

Department of Cellular and Structural Biology, University of Texas Health Science Center, San Antonio, TX 78229, USA protective effects of pre-treatment with melatonin $(10 \mathrm{nM})$ compared to the known beneficial effect of alpha-lipoic acid $(300 \mu \mathrm{M})$. Hydrogen peroxideinduced obvious oxidative stress; it increased the expression of tumour necrosis factor-alpha and in turn promoted nuclear factor kappa-B and overrode the endogenous defence mechanisms. Conversely, pretreatment of the hydrogen peroxide-exposed cells to melatonin or alpha-lipoic acid increased endogenous antioxidant enzymes, including superoxide dismutase2 and heme oxygenase-1; moreover, they ameliorated significantly oxidative stress damage and partially reduced alterations in the muscle cells, which are typical of aging. In conclusion, melatonin was equally effective as alpha-lipoic acid; it exhibited marked antioxidant and anti-aging effects at the level of skeletal muscle in vitro even when it was given in a much lower dose than alpha-lipoic acid.

Keywords Melatonin $\cdot \alpha$-Lipoic acid $\cdot$ Hydrogen peroxide $\cdot$ Oxidative stress $\cdot$ Skeletal muscle cell

\section{Introduction}

Since individuals in Western societies are living longer, there is an increasing necessity to understand the pathophysiological processes of aging. Aging is associated with the progressive accumulation of oxidative debris, which contributes to functional inefficiency of cells, thereby inducing additional free radical production and metabolic inefficiency. Thus, aging becomes a vicious 
cycle in which molecular processes fail resulting in accumulated oxidative damage causing physiological degeneration; this further exaggerates the production of free radicals (Cencioni et al. 2013).

A decline in skeletal muscle mass and function is a consequence of aging as well as of pathological processes including cancer, myopathies, and sepsis (Garatachea and Lucía 2013; Park et al. 2013). Muscle degeneration is characterized by the deregulation of calcium homeostasis, enhanced protease activity, loss of cytoskeletal and sarcolemmal integrity, impaired energy metabolism and oxidative stress, all of which contribute to muscle atrophy and degeneration (Hopf et al. 2007; Park et al. 2013).

Oxidative stress is a situation related to a serious imbalance between the production of oxidants, such as hydrogen peroxide $\left(\mathrm{H}_{2} \mathrm{O}_{2}\right)$ and superoxide anion $\left(\mathrm{O}_{2}{ }^{-}{ }^{-}\right)$, and antioxidant defence mechanisms culminating in cellular apoptosis or necrosis. The loss of cells due to programmed cell death is a consequence of/or contributes to many diseases as well as age-related deterioration (Halliwell 2003; Reiter 1995; Vinayaga et al. 2006). Skeletal muscle is particularly vulnerable to oxidative stress because it requires a large quantity of oxygen, and thus, muscle cells accumulate significant amounts of oxidative damage over time. Reactive oxygen species (ROS) damage many cellular components including DNA, lipid membranes and proteins (Aoi et al. 2004; Kozlovsky et al. 1997). Fortunately, cells also possess a variety of antioxidant defence systems. These include small molecules such as $\alpha$-tocopherol and ascorbic acid that intervene as sacrificial molecules in redox cycles (Harris 1992). Antioxidants also include specific inducible antioxidant enzymes such as superoxide dismutase (SOD), catalase, heme oxygenase (HO) and glutathione peroxidase which either convert oxygen radicals into less offensive products or prevent their formation (Devasagayam et al. 2004; Kozlovsky et al. 1997). As signalling molecules, ROS can activate numerous cellular stress-sensitive pathways, such as the phosphorylation of c-Jun N-terminal kinase (JNK) and nuclear factor kappa-B (NF-kB) (Min et al. 2009), which cause cell damage. Also, protein kinase signalling pathways are activated (Sebastián et al. 2012). Tumour necrosis factor- $\alpha$ (TNF- $\alpha$ ), a cytokine produced by monocytes and macrophages (Kozlovsky et al. 1997; Sprague and Khalil 2009), is a rapid and potent activator of NF-kB (Li 2003; Park et al. 2013; Sen et al. 1997). NF-kB, as a transcription factor, stimulates the expression of a number of genes related to oxidative stress, immune responses, inflammation and apoptosis. It is regulated in a complex manner by the ubiquitin-proteasome system; degradation of the NF-kB inhibitor, IkK, by the proteasome results in activation of NF-kB (Perkins 2007; Skaug et al. 2009; Vriend and Reiter 2014).

Melatonin is a small, highly conserved pineal secretory product with numerous receptor-mediated and receptor-independent actions (Reiter et al. 2007). Melatonin is perhaps best known for its mediation of circannual regulation of metabolism and reproductive competence in photosensitive species and its ability to influence circadian processes that are ubiquitous in organisms and in cells (Campos Costa et al. 2013). However, it is also well known for its ability to neutralize free radicals, reduce inflammation and defer agerelated dysfunction of several organs (Favero et al. 2014; Galano et al. 2015; Hardeland 2013; Reiter et al. 2014).

Alpha-lipoic acid (1,2-dithiolane-3-pentanoic acidLA) is a powerful antioxidant which might act by three distinct actions: (i) reactive oxygen species-scavenging activity; (ii) capacity to regenerate endogenous antioxidants, such as glutathione and vitamins $\mathrm{C}$ and $\mathrm{E}$ and (iii) metal-chelating activity (Arroll et al. 2014; Packer et al. 1995).

There are rather few studies that have compared the potential beneficial actions of melatonin with those of alpha-lipoic acid against induced atrophy and oxidative stress in a well-characterized in vitro model of skeletal muscle, rat L6 skeletal muscle cells (Dott et al. 2014; Jaiswal et al., 2015; Rachek et al. 2007). Herein, we first analysed the effects of oxidative stress induced by $\mathrm{H}_{2} \mathrm{O}_{2}$ on L6 myotubes; thereafter, we evaluated the protective effects of pre-treatment with melatonin and compared its antioxidant activity with the known beneficial effects of LA on L6 cells (Maddux et al. 2001).

\section{Material and methods}

L6 rat skeletal myoblasts, obtained from the Experimental Zooprophylactic Institute of Lombardy and Emilia Romagna "Bruno Ubertini", were cultured in Dulbecco's modified Eagle's medium (DMEM) supplemented with $10 \%$ heat-inactivated foetal bovine serum (FBS), penicillin $(100 \mathrm{U} / \mathrm{ml})$ and streptomycin $(100 \mu \mathrm{g} / \mathrm{ml})$ and incubated at $37{ }^{\circ} \mathrm{C}$ in a humidified atmosphere with $5 \%$ carbon dioxide and $95 \%$ air 
atmosphere. The cells, grown in monolayer, were allowed to differentiate and propagate, and the growth medium was replaced with differentiation medium composed of DMEM supplemented with $2 \%$ FBS, penicillin $(100 \mathrm{U} / \mathrm{ml})$ and streptomycin $(100 \mu \mathrm{g} / \mathrm{ml})$, as previously described by Park et al. (2013) and Vinayaga Moorthi et al. (2006). Reduction of serum allowed cell-to-cell fusion and formation of myotubes. In particular, the differentiation in myotubes was allowed to progress in 10-14 days and the medium was changed every $48 \mathrm{~h}$ before experimentation. Myogenic differentiation in myotubes was confirmed by morphological analyses using light microscopy, observing closely the alignment, elongation and the fusion of cells.

The L6 myoblasts were plated in culture six wells, induced to differentiate and randomly divided into the following experimental groups: control, control plus melatonin, control plus LA, hydrogen peroxide $\left(\mathrm{H}_{2} \mathrm{O}_{2}\right)$ treatment, melatonin pre-treatment and then $\mathrm{H}_{2} \mathrm{O}_{2}$ incubation, and LA pre-treatment and then $\mathrm{H}_{2} \mathrm{O}_{2}$ incubation. The cells of each experimental group were treated at confluence; L6 myotubes reached confluence in about 1 week.

The cells treated with melatonin were incubated for $24 \mathrm{~h}$ in a differentiation medium supplemented with powder of pure melatonin (Melapure ${ }^{\mathrm{TM}}$ by Flamma S.p.A., Chignolo d'Isola, Italy) at a final concentration of $10 \mathrm{nM}$, the maximal effective concentration as determined in a previous study of Park et al. (2013), in which melatonin, in a dose-dependent manner, significantly restored cell survival and attenuated oxidative stress generation and muscle cell proteolysis. Whereas, the myotubes, treated with LA for $24 \mathrm{~h}$, were added to powder of pure LA (Labochim S.p.A., Milan, Italy) at the final concentration of $300 \mu \mathrm{M}$, the maximal effective dose as determined by Maddux et al. (2001), which showed that LA protect L6 muscle cells from oxidative stress-induced insulin resistance in vitro. Melatonin and LA were directly added to the six-well culture plates, without changing the differentiation medium or washing, to avoid ROS production.

In other experimental groups, the myotubes were treated with $\mathrm{H}_{2} \mathrm{O}_{2}$ at the concentration of $50 \mu \mathrm{M}$ for $1 \mathrm{~h}$, as previously described by Blair et al. (1999). $\mathrm{H}_{2} \mathrm{O}_{2}$ is a toxic species that is widely used in cell studies to induce oxidative stress. It is often used as an exogenous oxidant treatment to promote free radical generation and proteolytic signalling pathways in both isolated skeletal muscles and in in vitro myotubes ( $\mathrm{Li}$ et al. 2003;
McClung et al. 2009). However, the concentration of $\mathrm{H}_{2} \mathrm{O}_{2}$ used in experiments differs widely in different cell types. In experiments conducted using myoblasts, a low concentration (1-10 $\mu \mathrm{M})$ of $\mathrm{H}_{2} \mathrm{O}_{2}$ was found to enhance growth, while moderate and high concentrations (50$300 \mu \mathrm{M}$ ) were detrimental to the cells (Caporossi et al. 2003; Orzechowski et al. 2002; Shao et al. 2012).

\section{Cell viability assay}

At the end of treatment, the myotubes were collected and resuspended in phosphate buffer solution (PBS), to which was added $0.4 \%$ trypan blue. Counts of viable (unstained) and non-viable (blue-stained) cells were made using a light microscope with a haemocytometer, and the percentage of viable cells was calculated, as previously reported by Rezzani et al. (2014). The assessment of cell viability was carried out by two independent observers blinded to cell treatments. In case of dispute concerning interpretation, the case was reconsidered until agreement was reached.

Measurement of myotube diameter

At the end of treatment, five images were collected per experimental well, and from each image, the 10 largest myotubes were measured using an image analyser (Image Pro Plus; Milan, Italy). In particular, the myotube diameter, expressed in micrometer, was calculated by two independent observers blinded to the experimental group analysed. The myotube diameter was calculated from the average of three independent measurements per myotube.

Immunofluorescence and morphometrical assay

At the end of the treatments, L6 cells of each experimental group were fixed in $4 \%$ buffered paraformaldehyde for $10 \mathrm{~min}$, washed in PBS and incubated in $0.3 \%$ bovine serum albumin for $1 \mathrm{~h}$ at room temperature and then overnight at $4{ }^{\circ} \mathrm{C}$ with the following antibodies: TNF- $\alpha$ (dilution 1:300; Santa Cruz Biotechnology Inc., Dallas, TX, USA), NF-kB (dilution 1:300; Abcam, Cambridge, UK), superoxide dismutase 2 (SOD2) (dilution 1:300; Abcam, Cambridge, UK) and heme oxygenase-1 (HO-1) (dilution 1:300; Abcam, Cambridge, UK). Thereafter, the myotubes were labelled with the respective conjugated secondary antibody (anti-goat or anti-mouse Alexa Fluor 546 or anti- 
rabbit Alexa Fluor 488-diluted 1:200; Life Technologies, Grand Island, NY, USA). Finally, the cells were counterstained with 4',6-diamidino-2phenylindole (DAPI), mounted and observed with a confocal microscope (510 Meta Zeiss, Oberkochen, Germany), as previously described by Rodella et al. (2013). The control for the immunofluorescence was performed by omitting the primary antibody and in the presence of isotype-matched total immunoglobulin $\mathrm{G}$.

Immunopositivity (staining intensity) of immunofluorescence analyses was computed by two independent observers blinded to the cell treatments using an optical fluorescent microscope equipped with an image analyser (Image Pro Plus; Milan, Italy). The immunopositivity was calculated by measuring, for each experimental group, 50 random fields with the same area $\left(0.04 \mathrm{~mm}^{2}\right)$, as previously described by Rezzani et al. (2014). The levels of immunopositivity are expressed as arbitrary units (AU). The data were pooled to calculate a mean value, and statistical significance of differences among the experimental groups was evaluated by ANOVA and Bonferroni test with significance set at $p<0.05$.

Tumour necrosis factor-alpha ELISA procedure

TNF- $\alpha$ concentration in cell lysates was measured using a commercial in vitro enzyme-linked immunosorbent assay (ELISA). In particular, we used a specific rat sandwich ELISA kit (Abcam, Cambridge, UK), according to manufacturer's guidelines. The optical density was determined at $450 \mathrm{~nm}$ in a microplate reader, and the TNF- $\alpha$ levels were expressed as $\mathrm{pg} / \mathrm{mL}$.

\section{Results}

Myotube viability and atrophy

The incubation of L6 cells with $\mathrm{H}_{2} \mathrm{O}_{2}$ for $1 \mathrm{~h}$ reduced cell survival by $17.8 \%(p<0.05)$; the dead cells that underwent apoptosis appeared 5 to $10 \mu \mathrm{m}$ in size. The majority of control myotubes, treated or not with melatonin, appeared normal in cells ranging from 10 to $18 \mu \mathrm{m}$ in size. Interestingly, $\mathrm{H}_{2} \mathrm{O}_{2}$-induced inhibition of cell survival was significantly alleviated by melatonin pre-treatment, increasing cell survival by $6.7 \%$ $(p<0.05)$ with respect to cells treated only with $\mathrm{H}_{2} \mathrm{O}_{2}$. Moreover, we observed that the treatment of L6 myotubes with LA caused the same trend in terms of survival as the melatonin-treated group; in particular, the pre-treatment of L6 cells with LA lowered cell death by $8.8 \%(p<0.05)$ relative to cell death induced by $\mathrm{H}_{2} \mathrm{O}_{2}$ only.

Myotube diameter was analysed as an indicator of skeletal muscle cell atrophy in response to $\mathrm{H}_{2} \mathrm{O}_{2}$ treatment. Myotube diameter decreased by $28.8 \%(p<0.05)$ in $\mathrm{H}_{2} \mathrm{O}_{2}$-incubated cells with respect to those in control cells, and pre-treatment with melatonin or LA increased the diameter by 24.4 and $23.2 \%(p<0.05)$, respectively (for more details see Fig. 1).

Interestingly, we observed that control cells treated or not with melatonin or LA for $24 \mathrm{~h}$ did not exhibit significant differences relative to cell vitality or morphological features; thus, we considered these as a single group defined generically as "control".

Oxidative stress and antioxidant defence

With regard to TNF- $\alpha$ staining (red colour in figures), $\mathrm{H}_{2} \mathrm{O}_{2}$ myotubes showed a strong/very strong immunopositivity; in contrast, control cells exhibited absent/very weak immunostaining and the cells pretreated with melatonin or LA both exhibited a weak expression (Fig. 2a-d). In particular, TNF- $\alpha$ staining exhibited a positive and diffuse staining at the cytoplasmic level with no positivity observed in the nucleus. Furthermore, these results are confirmed also by the quantitative measurement of TNF- $\alpha$ level in cell lysates (Fig. 2e).

NF-kB immunopositivity (green staining) was higher in $\mathrm{H}_{2} \mathrm{O}_{2}$-incubated cells compared to that in control myotubes; in particular, $\mathrm{H}_{2} \mathrm{O}_{2}$ incubation induced strong/very strong staining compared to an absent/very weak signal in control cells (Fig. 2f, g). The pretreatment with melatonin or with LA reduced NF-kB immunopositivity significantly, showing, respectively, very weak and weak/moderate signals (Fig. $2 \mathrm{~h}$, i). Of interest, NF-kB immunostaining was evident in the nucleus of cells and no positivity or very weak signal was observed at the cytoplasmic level. All findings related to oxidative stress markers were also confirmed by quantitative analyses, as summarized in Fig. 21.

The expression of SOD2 (green staining) was lower in $\mathrm{H}_{2} \mathrm{O}_{2}$-treated cells than in control myotubes, in which it was moderately expressed (Fig. 3a, b). However, both pre-treatment with melatonin or with LA increased SOD2 expression (Fig. 3c, d). In particular, $\mathrm{H}_{2} \mathrm{O}_{2}$ 

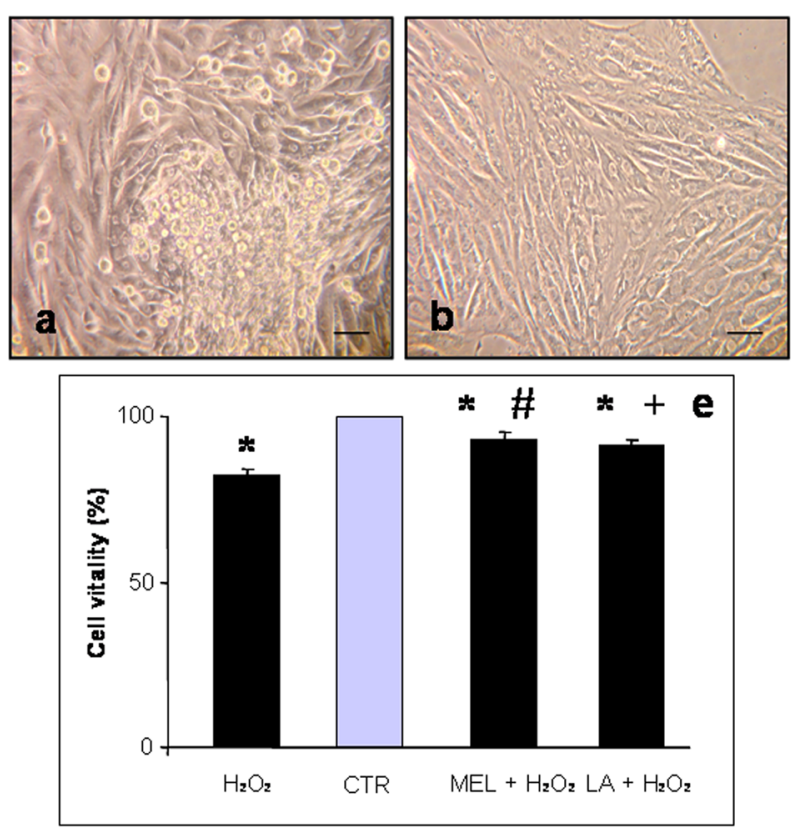

Fig. 1 Photomicrographs of L6 myotubes incubated with hydrogen peroxide- $\mathrm{H}_{2} \mathrm{O}_{2}$ (a), control-CTR (b), pre-treated with melatonin and then incubated in hydrogen peroxide- $\mathrm{MEL}+\mathrm{H}_{2} \mathrm{O}_{2}$ (c) or pre-treated with LA and then incubated in hydrogen peroxide - $\mathrm{LA}+\mathrm{H}_{2} \mathrm{O}_{2}$ (d). The myotube viability is expressed as

incubation induced a very weak expression compared to the pre-incubation period with melatonin or LA treatments causing, respectively, moderate and weak/ moderate signalling. Specifically, the immunopositivity was evident in the cytoplasm as "granules", suggesting mitochondrial SOD2 expression. No positivity was observed in the nucleus.

HO-1 immunostaining, identified in red, was weak in the $\mathrm{L} 6$ myotubes incubated in $\mathrm{H}_{2} \mathrm{O}_{2}$ relative to that in the control cells, in which there was no signal. Interestingly, pre-treatment with melatonin or LA increased significantly, with moderate/strong signals for $\mathrm{HO}-1$ expression (Fig. 3e, h). HO-1 immunostaining was evident in the cytoplasm of the myotubes and there was no positivity at the nuclear level. These observations were confirmed by morphometrical analyses, as summarized in Fig. 3i.

\section{Discussion}

Herein, we compared the effects of melatonin or LA on atrophy and oxidative stress of cultured rat L6 myotubes exposed to $\mathrm{H}_{2} \mathrm{O}_{2}$. In accordance with Blair et al. (1999), $\mathrm{H}_{2} \mathrm{O}_{2}$ was shown to be cytotoxic and induced growth
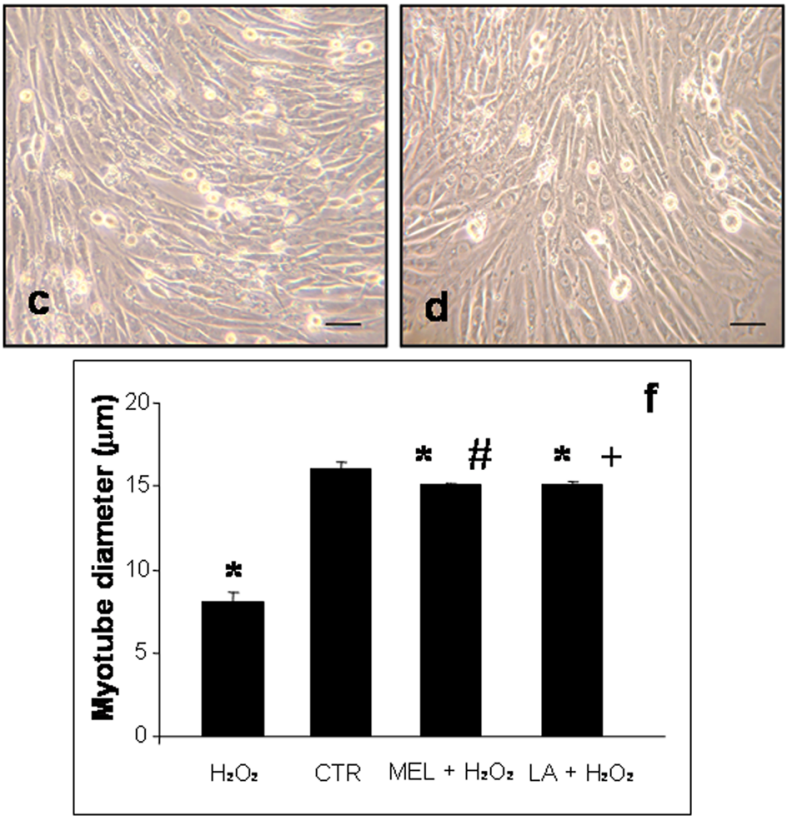

percentage of viable cells (e) and cell size as myotube diameter in micrometer (f). ${ }^{*} p<0.05$ vs control cells, $\# p<0.05$ vs hydrogen peroxide-treated cells and $+p<0.05$ vs pre-treated with melatonin and then incubated in hydrogen peroxide

retardation and cell death. $\mathrm{H}_{2} \mathrm{O}_{2}$ may also be an important molecule that regulates muscle growth; however, when its concentration is excessive or when the antioxidant defence is severely compromised, high levels of $\mathrm{H}_{2} \mathrm{O}_{2}$ cause pathology with consequent cell death via apoptosis and/or necrosis (Orzechowski et al. 2003). In our studies, it was shown that $\mathrm{H}_{2} \mathrm{O}_{2}$ did not induce mitogenicity, but it abrogated growth and induced oxidative stress, atrophy and apoptosis. Reduced mitogenicity in rat L6 muscle cells results from the oxidative/ nitrosative stress developed in response to ROS donors (Orzechowski et al. 2002; 2005).

Previous studies have demonstrated that oxidants and TNF- $\alpha$ stimulate NF-kB translocation into the nucleus as well as the expression of genes related to oxidative stress, cytokines and adhesion molecules in L6 cells (Aoi et al. 2004; Reid and Li 2001; Vriend and Reiter 2014); this is consistent with the current results. In particular, the results of the present study indicate that $\mathrm{H}_{2} \mathrm{O}_{2}$-induced oxidative stress was increased and endogenous antioxidant mechanism reduced after TNF- $\alpha$ stimulation and NF-kB translocation into the nucleus. Pre-incubation with melatonin or LA limited the atrophic and oxidative stress responses, which supports the 


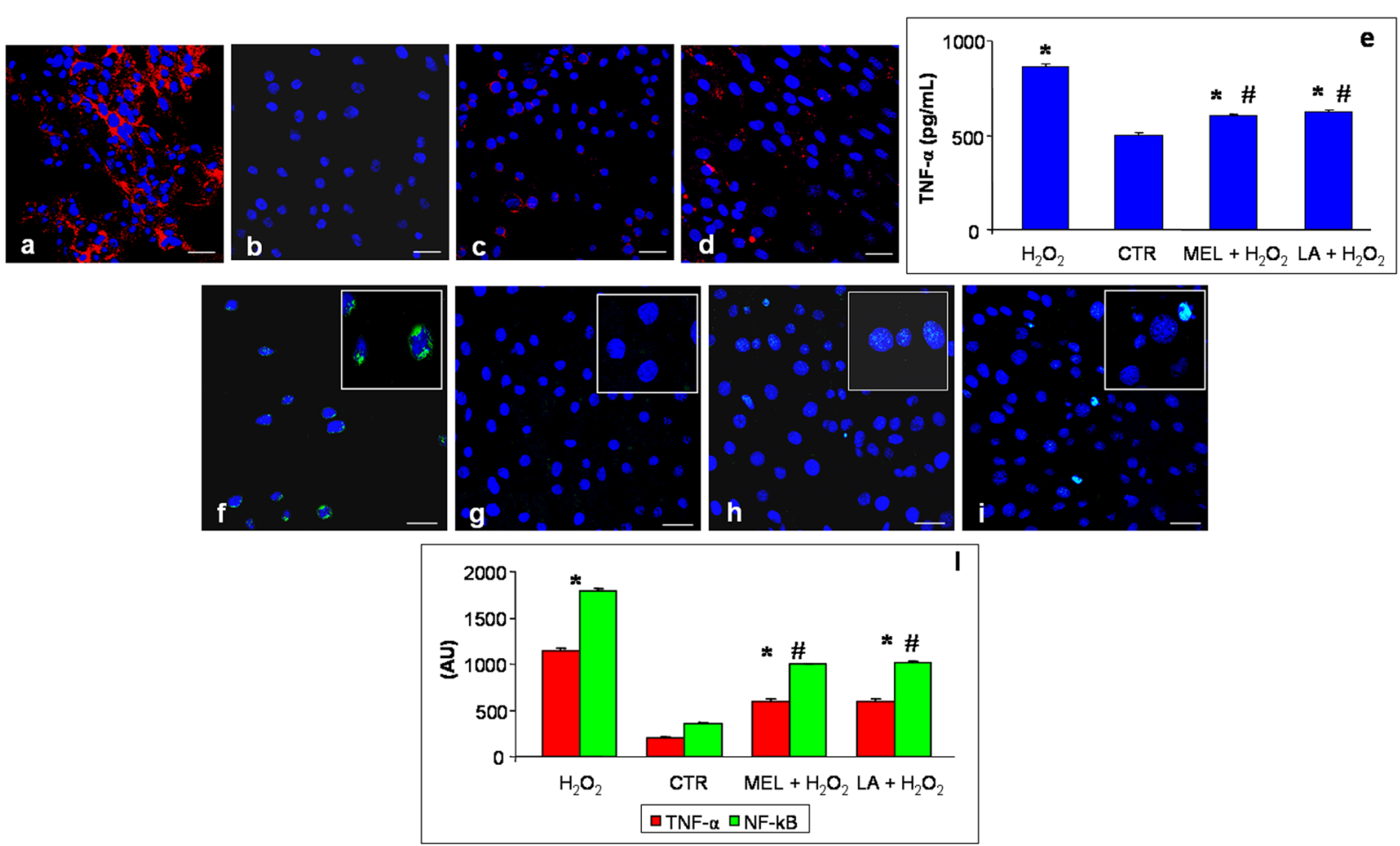

Fig. 2 Immunofluorescence analyses of tumour necrosis factor$\alpha-\mathrm{TNF}-\alpha(\mathbf{a}-\mathbf{d})$ and nuclear factor kappa-B-NF-kB (f-i) in L6 myotubes incubated with hydrogen peroxide $-\mathrm{H}_{2} \mathrm{O}_{2}(\mathbf{a}, \mathbf{f})$, control - CTR (b, g), pre-treated with melatonin and then incubated in hydrogen peroxide- $\mathrm{MEL}+\mathrm{H}_{2} \mathrm{O}_{2}(\mathbf{c}, \mathbf{h})$ and pre-treated with LA and then incubated in hydrogen peroxide- $\mathrm{LA}+\mathrm{H}_{2} \mathrm{O}_{2}(\mathbf{d}, \mathbf{i})$.

antioxidant and anti-aging properties of melatonin (Favero et al. 2014; Hardeland 2013; Reiter et al. 2014) and confirms the protective effect of LA against oxidative stress (Maddux et al. 2001).

Oxidative insults to cells are facilitated by the impairment in the function of endogenous antioxidant enzymes (Pandey and Rizvi 2011). In fact, the absence of a compensatory increase in endogenous antioxidant activity results in the activation of stress-sensitive signalling pathways (Dhanya et al. 2014). In this context, the concentration of $\mathrm{H}_{2} \mathrm{O}_{2}$ used in the current study was sufficient to induce cell death, resulting in a weak induction of endogenous antioxidants (SOD and HO-1) and a significant induction of oxidative stress and atrophy, as also reported by McClung et al. (2009) in C2C12 myotubes.

To reduce atrophy and oxidative stress, we pretreated the cells with melatonin or LA and observed that $\mathrm{H}_{2} \mathrm{O}_{2}$-induced apoptogenic effects were attenuated. Melatonin, acting both as a direct and indirect antioxidant, ameliorates mitogenicity also increasing SOD2
The insets show the NF-kB-positive nuclei of each experimental group. Scale bar $=20 \mu \mathrm{m}$. The graph (e) represents the quantitative measure of TNF- $\alpha$ in cell lysates $(\mathrm{pg} / \mathrm{mL})$ and summarizes the quantitative analysis of immunopositivities of both TNF- $\alpha$ and NF-kB (i). ${ }^{*} p<0.05$ vs control cells and $\# p<0.05$ vs hydrogen peroxide-treated cells

and HO-1 expression which, in turn, affected protein synthesis as did $\mathrm{H}_{2} \mathrm{O}_{2}$. Also, LA reduced oxidative stress and increased endogenous antioxidants, but with a less obvious protective effect than melatonin.

Fischer et al. (2013) reported a melatonin-mediated enhancement of the endogenous antioxidative enzyme activity network as an important and protective mechanism against ultraviolet radiation-induced oxidative damage to the skin. Interestingly, they observed that melatonin was not only an effective direct radical scavenger but also functioned as an indirect antioxidant through enhancement of antioxidative enzyme expression and as a counteracting substance against oxidative stress-induced DNA damage; these multiple mechanisms of action render melatonin a highly potent antioxidant against oxidative-induced damage.

In this study, we demonstrated that HO-1 activity is stimulated by both $\mathrm{H}_{2} \mathrm{O}_{2}$ and especially by melatonin pre-treatment in L6 skeletal myotubes and that this activation is associated with a concomitant important reduction in oxidative stress. Our results support the 

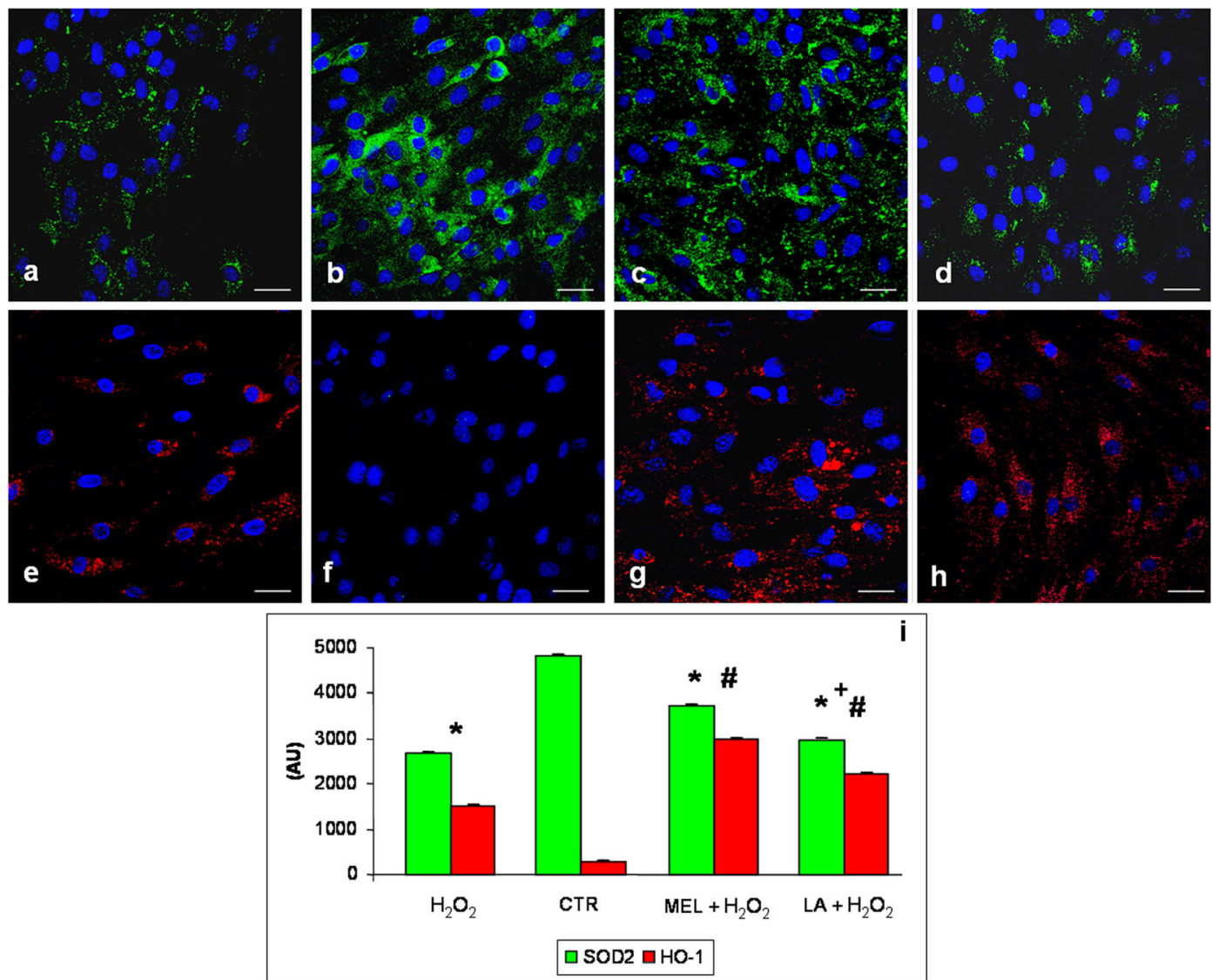

Fig. 3 Immunofluorescence analyses for superoxide dismutase 2-SOD2 (a-d) and heme oxygenase-1-HO-1 (e-h) in L6 myotubes incubated with hydrogen peroxide $-\mathrm{H}_{2} \mathrm{O}_{2}(\mathbf{a}, \mathbf{e})$, control - CTR $(\mathbf{b}, \mathbf{f})$, pre-treated with melatonin and then incubated in hydrogen peroxide-MEL $+\mathrm{H}_{2} \mathrm{O}_{2}(\mathbf{c}, \mathbf{g})$ and pre-treated with LA and then incubated in hydrogen peroxide- $\mathrm{LA}+\mathrm{H}_{2} \mathrm{O}_{2}(\mathbf{d}, \mathbf{h})$.

finding of Essig et al. (1997) in which it was postulated that HO-1 is stimulated in rat skeletal muscle and mediates cell adaptation to oxidative stress during muscle contraction. HO-1 is a strong candidate as a key player in protecting against skeletal muscle damage and has
Nuclei were stained with DAPI. Scale bar $=20 \mu \mathrm{m}$. The graph (i) summarizes the quantitative analysis of immunopositivities. $* p<0.05$ vs control cells, $\# p<0.05$ vs $\mathrm{H}_{2} \mathrm{O}_{2}$-treated cells and $+p<0.05$ vs pre-treated with melatonin and then incubated in hydrogen peroxide

been reported to perform this action in other cell types as well (Hirai et al. 2003; Lee et al. 2003; Vesely et al. 1998). The manner by which an increased activity of HO-1 can be cytoprotective is actually not known. A major function of $\mathrm{HO}-1$ is to catabolize heme to
Fig. 4 A schematic representation of hydrogen peroxide-mediated alterations in skeletal muscle cell and an illustration of the protective antioxidant and anti-aging effects of melatonin

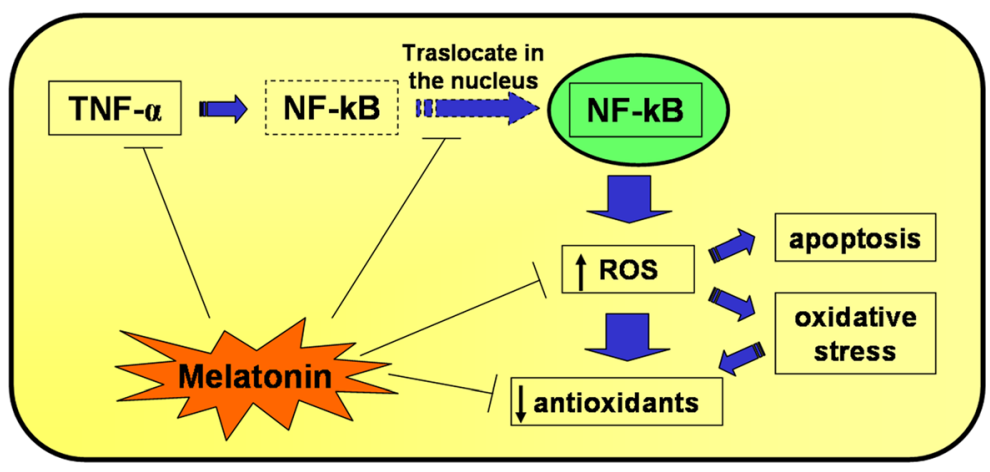


generate bilirubin, carbon monoxide and free iron, all of which may play direct or indirect roles in the cytoprotective effects of HO-1 (McArdle et al. 2004; Morse and Choi 2002).

Because induction of ROS production appears to play a central function in several diseases associated with aging, antioxidant upregulation represents a fundamental mechanism by which melatonin may exert therapeutic effects against oxidative stress and atrophy associated with these conditions. The protective effects of melatonin and its metabolites are currently attributed to melatonin's radical scavenging and antioxidant properties (Galano et al, 2013; Zhang and Zhang 2014). In this study, both direct and indirect antioxidant properties of melatonin were observed; this indoleamine directly scavenges a variety of the ROS including $\mathrm{H}_{2} \mathrm{O}_{2}$ and the highly deleterious hydroxyl radical (Reiter et al. 2002; Tengattini et al. 2008). Additionally, melatonin indirectly stimulates the expression and activity of antioxidant enzymes, including glutathione peroxidase, SOD, glutathione reductase and catalase as reported also by Park et al. (2013) and Rodriguez et al. (2004). In particular, Park et al. (2013) examined melatonin's potential to protect skeletal muscle cells against TNF- $\alpha$-induced muscle atrophy in an in vitro model and observed that it increased cellular antioxidant mechanisms.

Melatonin protects L6 myotubes from damage induced by $\mathrm{H}_{2} \mathrm{O}_{2}$ (Fig. 4); this effect might be achieved by maintaining the integrity of cellular integrity due to a reduction in oxidative stress and apoptosis and by increasing antioxidant defence responses thereby exerting a protective effect similar to that observed by Maddux et al. (2001) with LA pre-treatment. In the current study, we evaluated the protective actions of the pre-treatment with melatonin and compared its antioxidant activity with the known beneficial effects of LA. This comparison showed that melatonin pre-treatment was more efficient with respect to LA pre-treatment in increasing endogenous antioxidant enzymes (SOD2 and HO-1); this was especially obvious considering the respective concentrations of the molecules used, i.e., $10 \mathrm{nM}$ for melatonin and $300 \mu \mathrm{M}$ for LA. Since melatonin has both direct free radical-scavenging actions and the ability to promote antioxidant enzyme activities, it seems it may be a highly beneficial molecule to protect skeletal muscle not only from toxin or drug exposure but also from the degenerative changes associated with aging. However, what percentage of its benefits derives from each of the multiple actions of the indoleamine remains to be investigated.

In summary, the current findings document that oxidative stress imposed on L6 myotubes causes atrophy and molecular damage, but also an attempt of a compensatory adaptive response which results in a weak expression of antioxidants that in turn may activate cellular defence mechanisms. Since a reduction in oxidative stress is an important target for drug-based therapies and strategies to prevent damage during agingrelated diseases, discovering methods to attenuate it in all tissues including skeletal muscle could provide a means for protecting these vital cells from atrophy and aging-related pathophysiological processes. Further studies on this topic are mandatory in vitro, using also other additional skeletal muscle cell type, like $\mathrm{C} 2 \mathrm{C} 12$ myotubes. $\mathrm{C} 2 \mathrm{C} 12$ cells are grown as proliferative myoblasts and, upon reaching confluence, begin to differentiate, fusing into elongated, multinucleated and occasionally contractile fibres (Herbst et al. 2014), as L6 cells used in the present study. Moreover, to better assess the potential role of melatonin and LA as modulators of oxidative stress and skeletal muscle damage, other studies on their effect in combination will be an important and interesting issue for future study.

Acknowledgments Sincere thanks to FLAMMA S.p.A.-Italy (http://www.flammagroup.com) for courteously providing melatonin and to Miss Castrezzati Stefania for her technical support.

Open Access This article is distributed under the terms of the Creative Commons Attribution 4.0 International License (http://creativecommons.org/licenses/by/4.0/), which permits unrestricted use, distribution, and reproduction in any medium, provided you give appropriate credit to the original author(s) and the source, provide a link to the Creative Commons license, and indicate if changes were made.

\section{References}

Aoi W, Naito Y, Takanami Y, Kawai Y, Sakuma K, Ichikawa H, Yoshida N, Yoshikawa T (2004) Oxidative stress and delayed-onset muscle damage after exercise. Free Radic Biol Med 37:480-487

Arroll MA, Wilder L, Neil J (2014) Nutritional interventions for the adjunctive treatment of schizophrenia: a brief review. Nutr J 13:91

Blair AS, Hajduch E, Litherland GJ, Hundal HS (1999) Regulation of glucose transport and glycogen synthesis in L6 muscle cells during oxidative stress. Evidence for crosstalk between the insulin and SAPK2/p38 mitogen-activated 
protein kinase signaling pathways. J Biol Chem 274:3629336299

Campos Costa I, Nogueira Carvalho H, Fernandes L (2013) Aging, circadian rhythms and depressive disorders: a review. Am J Neurodegener Dis 2:228-246

Caporossi D, Ciafrè SA, Pittaluga M, Savini I, Farace MG (2003) Cellular responses to $\mathrm{H}(2) \mathrm{O}(2)$ and bleomycin-induced oxidative stress in L6C5 rat myoblasts. Free Radic Biol Med 35: 1355-1364

Cencioni C, Spallotta F, Martelli F, Valente S, Mai A, Zeiher AM, Gaetano C (2013) Oxidative stress and epigenetic regulation in ageing and age-related diseases. Int J Mol Sci 14:17643-17663

Devasagayam TP, Tilak JC, Boloor KK, Sane KS, Ghaskadbi SS, Lele RD (2004) Free radicals and antioxidants in human health: current status and future prospects. J Assoc Phys India 52:794-804

Dhanya R, Arun KB, Syama HP, Nisha P, Sundaresan A, Santhosh Kumar TR, Jayamurthy P (2014) Rutin and quercetin enhance glucose uptake in L6 myotubes under oxidative stress induced by tertiary butyl hydrogen peroxide. Food Chem 158:546-554

Dott W, Mistry P, Wright J, Cain K, Herbert KE (2014) Modulation of mitochondrial bioenergetics in a skeletal muscle cell line model of mitochondrial toxicity. Redox Biol 2: 224-233

Essig DA, Borger DR, Jackson DA (1997) Induction of heme oxygenase-1 (HSP32) mRNA in skeletal muscle following contractions. Am J Physiol 272:C59-C67

Favero G, Rodella LF, Reiter RJ, Rezzani R (2014) Melatonin and its atheroprotective effects: a review. Mol Cell Endocrinol 382:926-937

Fischer TW, Kleszczyński K, Hardkop LH, Kruse N, Zillikens D (2013) Melatonin enhances antioxidative enzyme gene expression (CAT, GPx, SOD), prevents their UVR-induced depletion, and protects against the formation of DNA damage (8-hydroxy-2'-deoxyguanosine) in ex vivo human skin. J Pineal Res 54:303-312

Galano A, Medina ME, Tan DX, Reiter RJ (2015) Melatonin and its metabolites as copper chelating agents and their role in inhibiting oxidative stress: a physicochemical analysis. J Pineal Res 58:107-116

Galano A, Tan DX, Reiter RJ (2013) On the free radical scavenging activities of melatonin's metabolites, AFMK and AMK. J Pineal Res 54:245-257

Garatachea N, Lucía A (2013) Genes and the ageing muscle: a review on genetic association studies. Age (Dordr) 35:207-233

Halliwell B (2003) Oxidative stress in cell culture: an underappreciated problem? FEBS Lett 540:3-6

Hardeland R (2013) Melatonin and the theories of aging: a critical appraisal of melatonin's role in antiaging mechanisms. J Pineal Res 55:325-356

Harris ED (1992) Regulation of antioxidant enzymes. FASEB J 6: 2675-2683

Herbst A, Aiken JM, McKenzie D (2014) Replication of prions in differentiated muscle cells. Prion 8:166-168

Hirai H, Kubo H, Yamaya M, Nakayama K, Numasaki M, Kobayashi S, Suzuki S, Shibahara S, Sasaki H (2003) Microsatellite polymorphism in heme oxygenase-1 gene promoter is associated with susceptibility to oxidant-induced apoptosis in lymphoblastoid cell lines. Blood 102:16191621
Hopf FW, Turner PR, Steinhardt RA (2007) Calcium misregulation and the pathogenesis of muscular dystrophy. Subcell Biochem 45:429-464

Kozlovsky N, Rudich A, Potashnik R, Bashan N (1997) Reactive oxygen species activate glucose transport in L6 myotubes. Free Radic Biol Med 23:859-869

Jaiswal N, Maurya CK, Arha D, Avisetti DR, Prathapan A, Raj PS, Raghu KG, Kalivendi SV, Tamrakar AK (2015) Fructose induces mitochondrial dysfunction and triggers apoptosis in skeletal muscle cells by provoking oxidative stress. Apoptosis 20:930-947

Lee HT, Xu H, Ota-Setlik A, Emala CW (2003) Oxidant preconditioning protects human proximal tubular cells against lethal oxidant injury via p38 MAPK and heme oxygenase-1. Am J Nephrol 23:324-333

Li YP (2003) TNF-alpha is a mitogen in skeletal muscle. Am J Physiol Cell Physiol 285:C370-C376

Li YP, Chen Y, Li AS, Reid MB (2003) Hydrogen peroxide stimulates ubiquitin-conjugating activity and expression of genes for specific E2 and E3 proteins in skeletal muscle myotubes. Am J Physiol Cell Physiol 285:C806-C812

Maddux BA, See W, Lawrence JC, Goldfine AL, Goldfine ID, Evans JL (2001) Protection against oxidative stress-induced insulin resistance in rat L6 muscle cells by mircomolar concentrations of alpha-lipoic acid. Diabetes 50:404-410

McArdle F, Spiers S, Aldemir H, Vasilaki A, Beaver A, Iwanejko L, McArdle A, Jackson MJ (2004) Preconditioning of skeletal muscle against contraction-induced damage: the role of adaptations to oxidants in mice. J Physiol 561:233-244

McClung JM, Judge AR, Talbert EE, Powers SK (2009) Calpain-1 is required for hydrogen peroxide-induced myotube atrophy. Am J Physiol Cell Physiol 296:C363-C371

Min W, Bin ZW, Quan ZB, Hui ZJ, Sheng FG (2009) The signal transduction pathway of PKC/NF-kappa B/c-fos may be involved in the influence of high glucose on the cardiomyocytes of neonatal rats. Cardiovasc Diabetol 8:8

Morse D, Choi AM (2002) Heme oxygenase-1: the "emerging molecule" has arrived. Am J Respir Cell Mol Biol 27:8-16

Orzechowski A, Grizard J, Jank M, Gajkowska B, Lokociejewska M, Zaron-Teperek M, Godlewski M (2002) Dexamethasonemediated regulation of death and differentiation of muscle cells. Is hydrogen peroxide involved in the process? Reprod Nutr Dev 42:197-216

Orzechowski A, Jank M, Gajkowska B, Sadkowski T, Godlewski MM, Ostaszewski P (2003) Delineation of signalling pathway leading to antioxidant-dependent inhibition of dexamethasone-mediated muscle cell death. J Muscle Res Cell Motil 24:33-53

Orzechowski A, Lokociejewska M, Pawlikowska P, Kruszewski M (2005) Preincubation with sodium ascorbate potentiates insulin-dependent PKB/Akt and c-Jun phosphorylation in L6 rat myoblasts challenged with reactive oxygen/nitrogen species. Life Sci 77:496-511

Packer L, Witt EH, Tritschler HJ (1995) alpha-Lipoic acid as a biological antioxidant. Free Radic Biol Med 19:227-250

Pandey KB, Rizvi SI (2011) Biomarkers of oxidative stress in red blood cells. Biomed Pap Med Fac Univ Palacky Olomouc Czech Repub 155:131-136

Park JH, Chung EJ, Kwon HJ, Im SS, Lim JG, Song DK (2013) Protective effect of melatonin on TNF- $\alpha$-induced muscle atrophy in L6 myotubes. J Pineal Res 54:417-425 
Perkins ND (2007) Integrating cell-signalling pathways with NFkappaB and IKK function. Nat Rev Mol Cell Biol 8:49-62

Rachek LI, Musiyenko SI, LeDoux SP, Wilson GL (2007) Palmitate induced mitochondrial deoxyribonucleic acid damage and apoptosis in 16 rat skeletal muscle cells. Endocrinology 148:293-299

Reid MB, Li YP (2001) Cytokines and oxidative signalling in skeletal muscle. Acta Physiol Scand 171:225-232

Reiter RJ (1995) The pineal gland and melatonin in relation to aging: a summary of the theories and of the data. Exp Gerontol 30:199-212

Reiter RJ, Tan DX, Galano A (2014) Melatonin: exceeding expectations. Physiology (Bethesda) 29:325-333

Reiter RJ, Tan DX, Manchester LC, Pilar Terron M, Flores LJ, Koppisepi S (2007) Medical implications of melatonin: receptor-mediated and receptor-independent actions. Adv Med Sci 52:11-28

Reiter RJ, Tan DX, Sainz RM, Mayo JC, Lopez-Burillo S (2002) Melatonin: reducing the toxicity and increasing the efficacy of drugs. J Pharm Pharmacol 54:1299-1321

Rezzani R, Rodella LF, Favero G, Damiani G, Paganelli C, Reiter RJ (2014) Attenuation of ultraviolet A-induced alterations in NIH3T3 dermal fibroblasts by melatonin. Br J Dermatol 170: 382-391

Rodella LF, Favero G, Rossini C, Foglio E, Bonomini F, Reiter RJ, Rezzani R (2013) Aging and vascular dysfunction: beneficial melatonin effects. Age (Dordr) 35:103-115

Rodriguez C, Mayo JC, Sainz RM, Antolín I, Herrera F, Martín V, Reiter RJ (2004) Regulation of antioxidant enzymes: a significant role for melatonin. J Pineal Res 36:1-9

Sebastián D, Hernández-Alvarez MI, Segalés J, Sorianello E, Muñoz JP, Sala D, Waget A, Liesa M, Paz JC, Gopalacharyulu P, Orešič M, Pich S, Burcelin R, Palacín
M, Zorzano A (2012) Mitofusin 2 (Mfn2) links mitochondrial and endoplasmic reticulum function with insulin signaling and is essential for normal glucose homeostasis. Proc Natl Acad Sci U S A 109:5523-5528

Sen CK, Khanna S, Reznick AZ, Roy S, Packer L (1997) Glutathione regulation of tumor necrosis factor-alphainduced NF-kappa B activation in skeletal muscle-derived L6 cells. Biochem Biophys Res Commun 237:645-649

Shao SX, Zhang L, Chen HX, Liu Y, Zhang JP, Chen W, Xue GY (2012) Diazoxide pretreatment enhances L6 skeletal myoblast survival and inhibits apoptosis induced by hydrogen peroxide. Anat Rec (Hoboken) 295:632-640

Skaug B, Jiang X, Chen ZJ (2009) The role of ubiquitin in NFkappaB regulatory pathways. Annu Rev Biochem 78:769-796

Sprague AH, Khalil RA (2009) Inflammatory cytokines in vascular dysfunction and vascular disease. Biochem Pharmacol 78: $539-552$

Tengattini S, Reiter RJ, Tan DX, Terron MP, Rodella LF, Rezzani R (2008) Cardiovascular diseases: protective effects of melatonin. J Pineal Res 44:16-25

Vesely MJ, Exon DJ, Clark JE, Foresti R, Green CJ, Motterlini R (1998) Heme oxygenase-1 induction in skeletal muscle cells: hemin and sodium nitroprusside are regulators in vitro. Am J Physiol 275:C1087-C1094

Vinayaga Moorthi R, Bobby Z, Selvaraj N, Sridhar MG (2006) Vitamin $\mathrm{E}$ protects the insulin sensitivity and redox balance in rat L6 muscle cells exposed to oxidative stress. Clin Chim Acta 367:132-136

Vriend J, Reiter RJ (2014) Melatonin as a proteasome inhibitor. Is there any clinical evidence? Life Sci 115:8-14

Zhang HM, Zhang Y (2014) Melatonin: a well-documented antioxidant with conditional pro-oxidant actions. J Pineal Res 57: 131-146 